\title{
An aesthetic for sustainable interactions in Product-Service System?
}

\author{
Fabrizio Ceschin \\ Politecnico di Milano, INDACO Department, Design and system Innovation for Sustainability (DIS) \\ Carlo Vezzoli \\ Politecnico di Milano, INDACO Department, Design and system Innovation for Sustainability (DIS) \\ Salvatore Zingale \\ Politecnico di Milano, INDACO Department, Communication Design (d.com)
}

Eco-efficient Product-Service System (PSS) innovations represent a promising approach to sustainability. However the application of this concept is still very limited because its implementation and diffusion is hindered by several barriers (cultural, corporate and regulative ones). The paper investigates the barriers that affect the attractiveness and acceptation of eco-efficient PSS alternatives, and opens the debate on the aesthetic of eco-efficient PSS, and the way in which aesthetic could enhance some specific inner qualities of this kinds of innovations. Integrating insights from semiotics, the paper outlines some first research hypothesis on how the aesthetic elements of an eco-efficient PSS could facilitate user attraction, acceptation and satisfaction.

\section{Eco-efficient Product-Service System (PSS) innovation: a promising approach to sustainability}

It is widely shared that the transition towards sustainability will require a system discontinuity, meaning that a radical redefinition of the current structures of production and consumption is needed. In the second half of the '90s a series of studies and analyses led to a clearer understanding of the dimension of change necessary to achieve a society that is effectively and globally sustainable. These studies indicate that in 50 years, considering the raising consumption levels and the doubling of the world's population, a sustainable society should use 90\% less resources than industrialised countries are doing today (Factor 10 Club, 1994; Schmidt-Bleek, 1996; WBCSD, 1996). In other words, conditions for sustainability can only be achieved by drastically reducing the consumption of environmental resources compared to the current average consumption in mature industrialised contexts.

Given the dimension of the required change it is therefore clear that innovations on a process and product level, although being fundamental and necessary, are not alone sufficient to obtain the just mentioned radical shift. In fact, although it is true that these innovations can improve environmental performances of products (by a factor of 2-4 for Charter and Tischner, 2001), it is also true that these improvements are often negatively counterbalanced by an increase in consumption levels (Haake and Jolivet, 2001). In addition it has to be underlined that in the traditional production and consumption model, based on the traditional sale of products, producer's economic interest usually does not converge with an environmental interest in optimizing the resources consumed (Mont, 2002; UNEP, 2002). 


\section{Sustainability in Design: NOW!}

For these reasons, if we want to effectively tackle sustainability, there is a need to move from a focus on product improvements only, towards a wider systemic approach that takes in consideration new potential ways of satisfying the social demand of wellbeing. In this perspective, as suggested by Stahel (1986, 1989), we should move from an industrial economy, in which the central value is based on the exchange of products to be consumed (e.g. cars; boilers and methane; washing machines and powder), to a functional economy, in which products are mere means of providing functions (e.g. mobility; thermal comfort; having clean clothes). Its economic objective is to create the highest possible use value for the longest possible time while consuming as few material resources and energy as possible; thus it is potentially more dematerialised than the present economy, which is focused on production and related material flows as its principal means to create wealth (Stahel, 1986; 1997). In other words a functional economy can potentially bring about a reduction in the current levels of resources consumption, without minimizing consumers' level of satisfaction (UNEP, 2002; Mont, 2004a; Tukker and Tischner, 2006).

Within this perspective several authors consider promising to look at the concept of Product-Service System (PSS) innovation, understood as the result of an innovative strategy that shifts the centre of business from the design and sale of (physical) products alone, to the design and offer of an integrated system of products and services that are together able to fulfil a particular demand of satisfaction (UNEP, 2002). In fact, if properly conceived, this kind of innovation can potentially bring companies to improving their competitiveness and at the same time to separating resources consumption from its traditional connection with profit (Goedkoop et al., 1999; Brezet et al., 2001; Manzini \& Vezzoli, 2001; UNEP, 2002; Tukker \& Tischner 2006; Mont, 2004). These PSS can be defined eco-efficient PSS (UNEP, 2002; Vezzoli, 2007), meaning that is the economic interest of the socio-economical stakeholders (involved in the PSS offer) that foster an optimisation of the environmental resources consumption, i.e. PSS are potentially ecoefficient since they are capable of decoupling resource consumption and environmental impacts from value creation for both the company and the customer (Tischner, Rayan and Vezzoli, 2009)

An illustration of the potential environmental benefits of a PSS is clear in the "Pay-per-use" solution offered by Ariston (an Italian washing machine manufacturer). Here, rather than selling a washing machine, Ariston provides access to it enabling clients to get their "satisfaction", i.e. "having clean cloths". The payment is based on number of washes and includes delivery of a washing machine at home (not owned by the customer), electricity supply (not directly paid by the customer), maintenance, and end-oflife collection. Within this business model Ariston is economically incentivised in reducing as much as possible the washing machine energy consumption (in order to reduce operational costs and maximise profits), and in designing and providing long lasting, reusable and recyclable washing machines (in order to postpone the disposal costs and the costs for the manufacturing of new washing machines).

From what has been said it is possible to identify three key elements that characterise this kind of innovations:

- they are rooted in a satisfaction-based economic model, i.e. instead of the traditional forms of selling, ownership, use and disposal, an eco-efficient PSS is focused on delivering a particular satisfaction to the user, even referred as "unit of satisfaction" (Vezzoli, 2007); and this through an integrated set of products (owned by the producer/s and/or provider/s) and services. In other words there is a shift from a ownership-based consumption to an offer based on access and (in some cases) sharing;

- they are stakeholder interactions-based innovation, i.e. they are radical innovations, not so much as technological ones, as new interactions/partnerships between the stakeholders of a particular value/satisfaction production system, showing a fundamental shift in the relationships between the user and the producer/provider; it is in fact a relationship that does not end right after the sale, but continues during the whole duration of the service.

- they have an intrinsic eco-efficiency potential, i.e. they are innovations in which is the company/companies' economic and competitive interest that may leads to an environmental impact reduction (system eco-efficiency: decoupling the creation of value from resources consumption).

In the last 15 years the European Union has dedicated special attention to this kind of innovations: a wide number of research projects in the field of PSS and sustainability have been supported by EU funding. These researches brought to clarifying the concept of PSS, understanding its characteristics, potential benefits, drivers \& barriers, possible rebound effects, etc., and to developing (and partly testing) different methods and tools to orient and support the design of eco-efficient PSSs (see for example: Brezet et al., 
2001; Manzini, Collina and Evans, 2004; Van Halen, Vezzoli and Wimmer, 2005; Tukker and Tischner, 2006; Tischner, Rayan and Vezzoli, 2009).

However, despite all the knowledge developed at academic level, and despite its win-win potentials, the extent to which companies have adopted this kind of business model is still very limited. In effect, even if the concept of PSS is recognized as a potential win-win solution (winning for the producers/providers, the users and the environment), its adoption by companies faces different barriers. This is because eco-efficient PSS are usually radical innovations: innovations that challenge existing company models and existing regulatory framework, and at the same time foresee new relations between users and producer/provider. Within this perspective different barriers can be identified (UNEP, 2002; Mont, 2002). On the company side, usually there are difficulties in changing the corporate culture and the traditional business concept, because there are uncertainties about cash flows, and because new design and management skills are required. From the customer point of view, the main problems are the cultural shift necessary in accepting an ownerless consumption, and the lack of knowledge about life cycle costs. In addition, on the regulative side, there are difficulties in implementing policy measures to create corporate drivers to facilitate the promotion and diffusion of this kind of innovations.

Starting from these considerations the paper firstly investigates the barriers that affect the attractiveness and acceptation of eco-efficient PSS alternatives. Then the paper opens the debate on the aesthetic of eco-efficient PSS, and the way in which aesthetic could enhance some specific inner qualities of ecoefficient PSS, i.e. facilitating and enhancing their wider diffusion. Through the analysis of some case studies, and integrating insights from semiotics, the paper then outlines some first research hypothesis on how the aesthetic elements of an eco-efficient PSS could facilitate user attraction, acceptation and satisfaction.

\section{Eco-efficient Product-Service System (PSS): user acceptation barriers}

Consumption behaviour is a matter of individual choice, influenced by social norms and institutional settings. The diffusion of alternative eco-efficient PSS solutions is hindered by the current and dominant consumption behaviours. Let's summarise the most important factors that determine this opposition (in industrialised contexts); we will follow Mont (2004b) line of thought, dividing these factors in economic and socio-psychological ones.

From an economic perspective, Røpke (1999) states that the current consumption behaviours are firstly determined by the entire history of industrial development. The industrial revolution brought to increased production volumes and reduced products prices, determining the need to sell more and more new products. This brought to create the demand for all the produced artefacts and therefore strategies were defined to encourage and boost consumption. In relation to this, Kilbourne et al. (2001) state that the economic and political institutions have persuaded people to believe that higher material prosperity is the expected behaviour.

Another cause that is bringing to reinforce material consumption levels is related to the so called externalities. Since environmental and social costs connected to products are not included their market prices, it becomes hard for eco-efficient PSS solutions to compete with the industrially produced products (Mont and Lindhqvist, 2003; Ceschin and Vezzoli, 2010). Moreover the prices of labour intensive solutions (and eco-efficient PSS is most of the time included in this category) are increasing, and therefore it is cheaper for customers to buy product-based offers (e.g. washing machines) instead of PSS-based offers (e.g. clothing care services).

In addition it has to be underlined that users show a lack of knowledge and understanding about life cycle costs (Mont, 2002). For this reason it becomes sometimes difficult for them to understand the potential economic benefits of a PSS oriented solutions. PSS-based offers are usually (and erroneously) perceived by the end-user more expensive if compared to the purchase of products (even if sometimes it is true the contrary), since the use, the maintenance, the repair and the disposal costs are in fact not taken in consideration during the product purchase.

Economic studies are traditionally based on the assumption that consumers are rational decision makers whose choices are driven by utility maximisation, with price and income factors as the most important ones in taking choices. However, as underlined by Mont and Plepys (2008) consumer behaviour has been 
found to be far more complicated than just a rational response to prices, being influenced by different internal and external drivers induced by human psychology, social norms and institutional settings.

Sociological studies underline the role of habits in influencing consumption behaviour, arguing that consumption choices are dependent by prior consumption patterns. In relation to eco-efficient PSS, the problem is that solutions based on sharing and access contradict the dominant and well established norm of ownership (Behrendt et al., 2003), making consumers hesitant in accepting ownerless-based solutions. And this is especially true for particular types of satisfaction (e.g. for washing our clothes we are not used to think that we could have in our home a washing machine that does not belong to us), while in other cases ownerless-based solutions have entered in our routines (e.g. the use of public transport services).

Another barrier to the diffusion of ownerless-based solutions is the fact that the quantity and quality of accumulated goods is perceived as a measure of success in life, because they represent an indicator of a certain position in society (Mont, 2004b). Moreover, as underlined by Halkier (1998), the current trend towards individualisation is boosting the consumption demand, because person's identity is no longer defined by a community, rather by the goods she/he owns (goods that represent the signals of one's own identity).

In addition, the hesitation towards offers based on ownerless access and sharing can also be linked to the perception of independency, hygiene and intimacy usually connected to one's own products.

Even if there are barriers that obstacle the acceptation of ownerless-based offers, it has also to be underlined there are also some windows of opportunity (Mont, 2004b) that can be exploited to favour the acceptation of such a kind of solutions. Firstly, while traditional economics argues that users demand physical products to satisfy their needs, the works of some sociologists (among other Max-Neef, 1991) tells us that needs can be fulfilled by material and non-material "satisfiers". Moreover material consumption is not linked to happiness; in fact more materialistic people are not always more happy than less materialistic ones (Belk, 1985; Max-Neef, 1995). In addition, some studies state that increase in consumption levels represent the need to satisfy psychological and social aspirations rather than material ones (Jackson and Mark, 1999). On the same line of thought, Hacker (1967) argues that the purchase of the same brand represents a substitute for a lost sense of community. Moreover, in relation to goods possessions, even if is true that this is perceived as a measure of a certain social status, it has also to be said that ownerless solutions may also represent a certain status; let's think for example to the use of taxi, access to education or cultural events (Mont, 2004b).

We have seen that different barriers on a user level may obstacle the acceptation and the satisfaction related to ownerless-based solutions. At this point the key questions that arise are:

- how it is possible to make the user to accept the (radical) behavioural changes linked with this kind of solutions? How is it possible to favour the embedding process into his/her habits?

- during the purchase choice, how could we make the user to be more attracted by an eco-efficient PSS rather than a traditional product-based offer?

- during the use, how could we make the user to perceive an eco-efficient PSS more satisfying than a traditional "product-based" offer? In other terms how an eco-efficient PSS can be perceived as a solution that produces more comfort, usage pleasure, etc. than a traditional offer?

\section{A potential role of aesthetic in enhancing the attraction, acceptation and satisfaction related to eco-efficient PSS?}

The first consideration that can be done is that an aesthetic of an eco-efficient PSS (that is to say the way in which it is perceived by the user) may play a key role in enhancing user attraction, acceptation and satisfaction. In other words, it is fundamental to focus on the way in which the different elements of an eco-efficient PSS are perceived. And as we have seen before, an eco-efficient PSS is a quite complex artefact, made up of different elements: products, communication, services (interactions between the user and the producer/provider) and more in general interactions (between the different socioeconomical stakeholders involved in the PSS value production system). So, the attraction, acceptation and 
satisfaction related to a PSS depend on how its system of products, services and interactions (and its inner qualities) are perceived by the user.

We know that aesthetic has an important role in product design and in user acceptance and satisfaction. So forth aesthetic has a role to play in product design for sustainability as far as a new generation of products has to substitute the unsustainable products we are surrounded by (in industrialised contexts). Moving on a system innovation level the question is: in which sense it possible to think about an aesthetic of eco-efficient PSS? This question is not only related to the debate on design for sustainability, but more widely on the role of design.

A preliminary assumption (justified by all has been said in the previous paragraphs) is that there is a need to explore aesthetic potential role in this field.

A following understanding is that such an aesthetic should take in consideration not only the products related to a PSS, but also the services and more in general the various interactions. We could talk of a system aesthetic, i.e. an aesthetic as the integrated perceptions of the "expressions forms" of the different elements of the PSS: an aesthetic that therefore integrates in a coordinated way the aesthetics of products, communication, services and interactions.

Starting from these considerations the question is: how the aesthetic elements of an eco-efficient PSS could facilitate user attraction, acceptation and satisfaction? In order to try to outline a framework for possible answers, we will analyse some cases of eco-efficient PSS (to get some insights), and we will put forward some working hypothesises.

\section{Insights from case studies}

\section{Wash bar}

Wash bar (Tamborrini, 2009) is a LG Electronics laundry, inaugurated in 2005 in Paris. Users have access to washing machines and dryers, but also to a bar and various recreational-cultural services, like wifi internet connection, short films projections, and participation to organised events. The interior spaces appear like a bar or a game room in which the last generation washing machines and dryers are integrated.

The environmental benefits connected to this kind of solutions are clear. The question is: what are the differences between Wash bar and the traditional laundries? First of all it is possible to say that in Wash bar there is the intention to approach a wider range of users, and stimulate more persons to adopt this kind of solution. The adopted strategy is simply to make pleasant the waiting time during the washing and drying cycle. The various elements of the system (the furniture elements, the communication elements, and the service elements) are thought and arranged in order to create a sense of hospitality. Users can feel at home: they can read, listen to music, surf on internet.

\section{Figure 1 and 2. Wash bar: pictures of the interior spaces.}

Source: Tamborrini, 2009
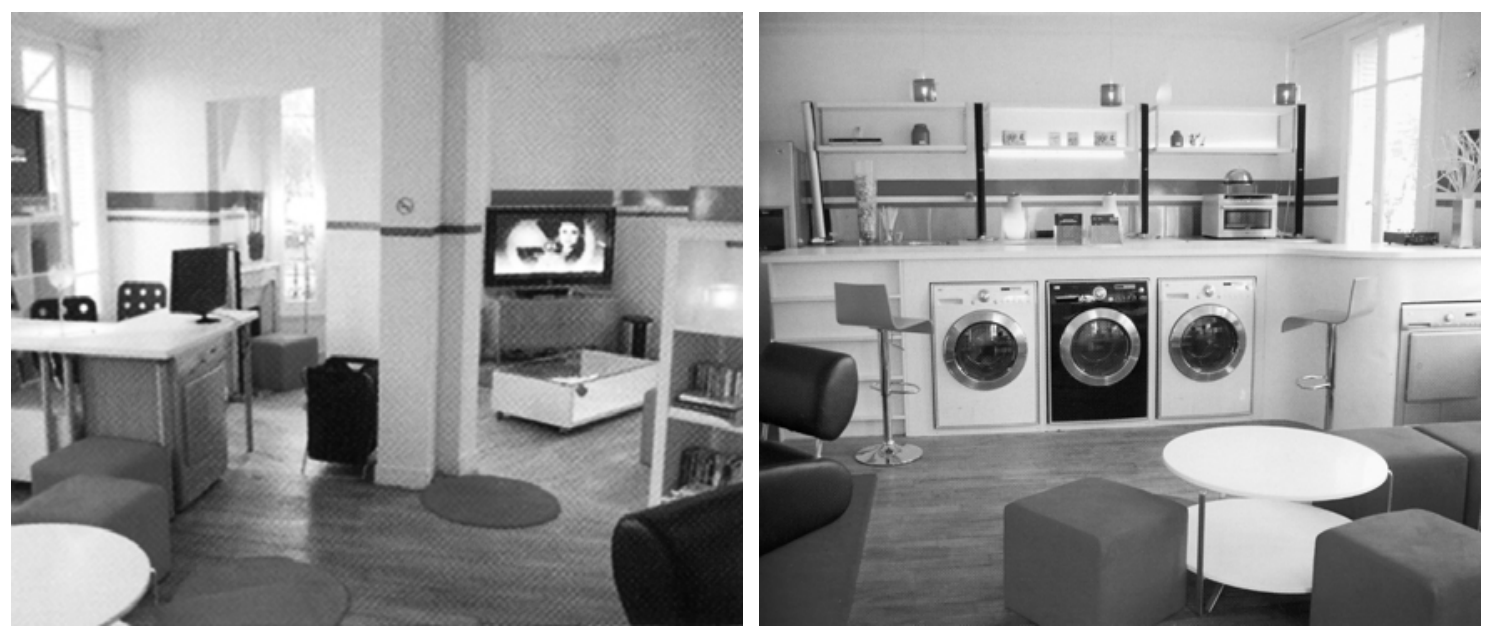


\section{Sustainability in Design: NOW!}

But the main aspect is linked to the social dimension of the solution. In fact the different tangible elements (sofas, armchairs, tables, etc, and their layout), coupled with the various available services (bar, wifi connection, etc.), together determine the possibility for users to develop interpersonal relations. And it's just this relational aspect that represents the key point of the PSS solution. It is the social quality of the innovation that can potentially contribute to make the solution perceived as more satisfying compared to the traditional laundries (and maybe also to the domestic wash).

\section{Car sharing/pooling system for the Vehicle Design Summit project}

The second case we present is a urban car sharing/pooling developed as a master degree thesis by Lorenzo Davoli within the research project Vehicle Design Summit ${ }^{0}$.

In synthesis (Vezzoli and Ceschin, 2008) it is a system through which users have access to a fleet of low environmental impact cars, and in which users are stimulated to share trips with other persons. User, once registered, receives a smart card that allows the access to the fleet of electric cars as well as to the public transports. The reservation of the car (displaced in dedicated parking lots made available by the public administration), is done via internet or cell phone. During the use of the vehicle a GPS system suggests user in choosing the shortest and least and crowded route. The payment of the service is based on the kilometres covered.

The peculiarity of this system is that through internet user can create and manage the own network of contacts (friends, colleagues, relatives, neighbours, etc.), and through this network organise the own trips, and plan to share them. Moreover, through the cell phone it will be possible to know in real time the position of the friends that are using the car, and in case ask them a lift (sharing the service costs).

\section{Figure 3. Car sharing/pooling system designed for the Vehicle Design Summit project: storyboard of one of the possible user interactions.}

Source: Elaboration starting from images made by Lorenzo Davoli (Davoli, Fiocchi and Lin, 2008)

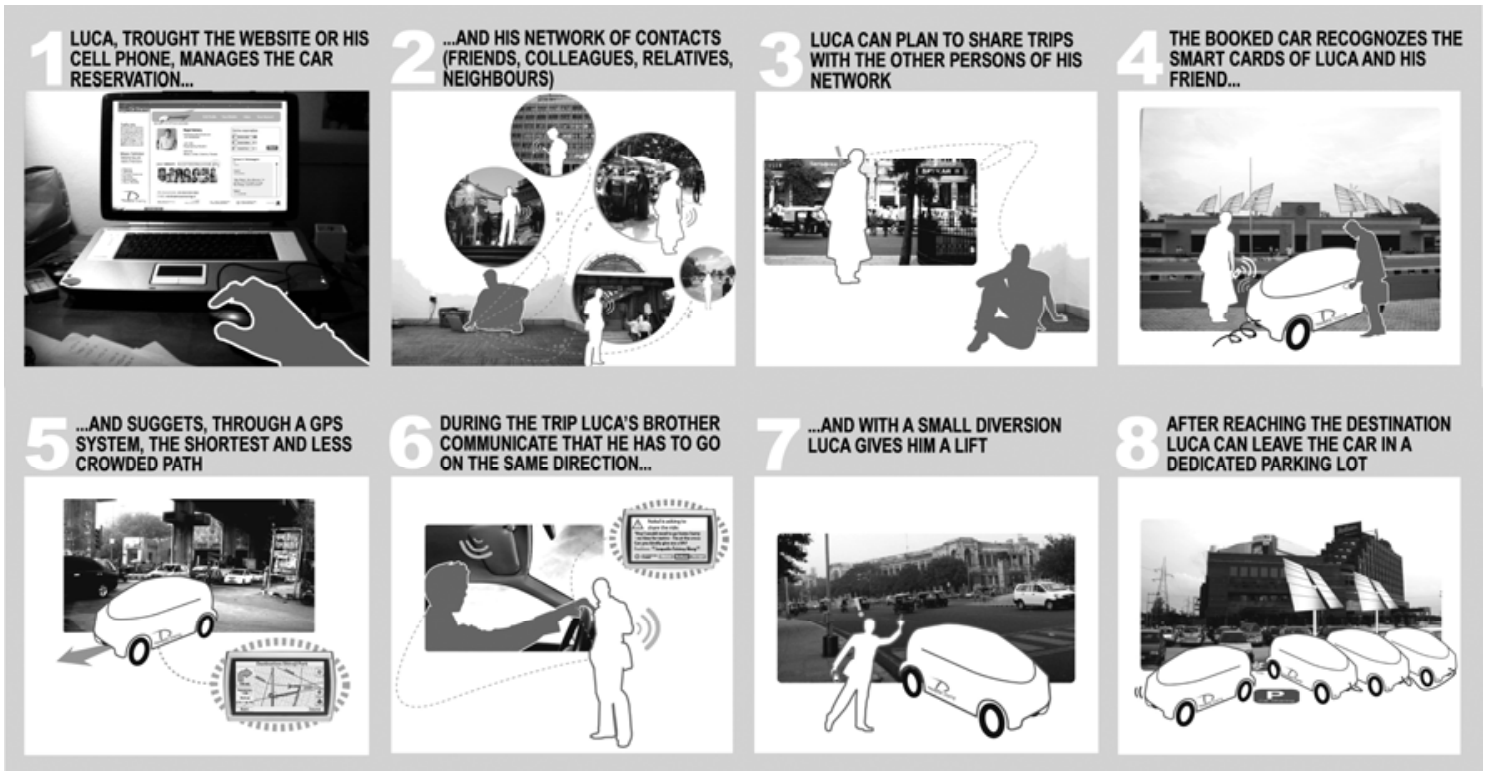

The environmental advantages of car sharing/pooling systems, compared to use of a private car, are obvious. The question is: what are the differences between this system and the traditional ones? Like in the previous case, there is the intention to make the solution more satisfying if compared to the traditional car sharing systems and the use of private cars. And even in this case the fulcrum is represented by the aspects linked to the relational qualities. The key point is in fact the possibility to create and manage a network of contacts with whom share trips. In this way users can build new contacts as well as feel part of

\footnotetext{
${ }^{0}$ Vehicle Design Summit is an international consortium made up of 27 universities and coordinated by MIT of Boston. The consortium objective is to design and realise a low environmental and "open-source" car, as well as the definition of the conditions for its market introduction through innovative and sustainable mobility offers. The role of Politecnico di Milano team (Lorenzo Davoli, Francesca Fiocchi and Jun Lin, coordinated by Carlo Vezzoli and Fabrizio Ceschin), was to design an innovative and eco-efficient business model, as well as a transition path to introduce and diffuse this model into the market.
} 
a community. And it is this social dimension of the service that could act as a stimulus to modify user habits and behaviours.

It has also to be said that, to support this change, the system is designed also to create awareness about environmental issues. The service in fact on one hand supports user in choosing the less crowded paths (with a consequent resources saving) on the other explain the environmental benefits connected to the system. And this represents a further element potentially capable to strengthen the acceptation of such kinds of solutions.

\section{A design research working hypothesis}

At this point a proper question is: which effects should the aesthetic of an eco-efficient PSS produce on the user?

First of all it has to be remarked that eco-efficient PSS are satisfaction-based offers, meaning that what is designed is a "unit of satisfaction", rather than the product that permit to obtain it. In this perspective:

- the aesthetic dimension, and so forth the delivery of the perceived value can be designed onto the ultimate and profound level of the offer (i.e. the satisfaction rather than on the various means to reach it); in this sense the same aesthetics (as attraction, acceptation, and satisfaction) is more "honest" and "transparent" to the user.

Moreover, as we have seen before, since eco-efficient PSS are based on ownerless access (of products or final results), and sharing (of products), it is on the advantages connected to these characteristics that it is necessary to focus on in order to make such a solutions perceived as better than the traditional productbased offers. In particular eco-efficient PSS can potentially favour:

- the interactivity between the various users (of the PSS). The sharing of products between more persons can in fact bring to the development of new interpersonal relations (let's think for example to the previous described cases). The direct contact between persons, that take place during the use of a PSS, can determine a greater participation of the user, who can feel "part of a community": let's think for instance to the solidarity purchasing groups (organised groups of people which buy food directly from local farmers) and the relations that take place between the users.

- the interactivity between user and the PSS producer/provider, because the relationship does not end after the purchasing (as happen in the traditional product-based offers) but last in time for the length of the stipulated contract/agreement.

These elements (the relational qualities that can be built between the users of a PSS, and between them and the producer/provider) are the ones that usually cannot be found in the traditional product-based solutions. Therefore they represent some distinctive traits of eco-efficient PSS. Thus, these relational qualities should be the elements to be valorised if we want to enhance user attraction, acceptance and satisfaction.

This is coherent to what we have seen before. In fact, if goods purchase can be linked to the need to satisfy social aspirations (Jackson and Mark, 1999), and can represent a substitution for a lost sense of community (Hacker, 1967), it is especially on these social processes that a PSS should focus on (in order to be perceived better than a product-based solution).

In addition to these elements, an eco-efficient PSS is also characterised for its intrinsic environmental and economic benefits. The problem is that, as underlined in chapter 2, most of the time user is not aware about these qualities. As consequence it is necessary to focus also on these aspects if we want to enhance the attraction and acceptation of these kinds of solutions. In particular:

- it is necessary to favour users in understanding the environmental and economic benefits connected to the use of eco-efficient PSS solutions;

- as consequence, users will become aware of having acquired and adopted a more responsible and sustainable behaviour; and this could represent a flywheel for a wider diffusion of the solution (because users could inform and stimulate other persons in doing the same). 
It has also to be said that eco-efficient PSS, compared to traditional ownership-based solutions, usually bring to users further benefits, as:

- the release from the problems and costs connected to the products maintenance repair and disposal.

As consequence even this aspect should be emphasised and made more visible to the users.

Finally it has to be remarked that eco-efficient PSS not only have to create satisfaction during the use phase, but they also have to be more attractive (compared to ownership-based offers) during the purchase choice. In other words eco-efficient PSS should be capable to "invite" and "intrigue" users (and attract their interest) more than the product-based solutions.

In synthesis, how the aesthetic elements of an eco-efficient PSS could facilitate user attraction, acceptation and satisfaction? Some working hypothesis (to be verified):

- during the purchase choice, the aesthetic elements of an eco-efficient PSS should stimulate users in attracting and inviting their interest;

- during the use phase, the aesthetic elements of an eco-efficient PSS should valorise its relational qualities (stimulating interactivity between users, and between them and the PSS producer/provider);

- during the use phase, the aesthetic elements of an eco-efficient PSS should facilitate users in understanding the advantages related to the release from the problems and costs connected to the products maintenance and disposal;

- during the use phase, the aesthetic elements of an eco-efficient PSS should also facilitate users in understanding and enjoying its various economic and environmental benefits.

\section{Semiotics, aesthetic and eco-efficient PSS}

\section{The meaning of relations}

Relationships are of central importance to semiotics. The meaning of words and things always arises from the way the different elements of human experience meet and associate. Both in text analysis and in product and service design, a particularly important type of relationship is that between the expression plane and the content plane (cf. Hjelmslev, 1943). The expression concerns the way in which things occur: the form they take, the syntactic arrangement of their components, the materials of which they are composed. Expression is both the logical organization of the products and their perceptible appearance. Instead, the plan of content covers the entire semantic background of the artefacts: the range of their possible meanings and the meaning of their existence, but not only. When we talk about products and services, the semantic dimension also concerns the sphere of those social relations in which they are located and, thus, those functions and modalities of use that make them operational.

The social use of products identifies another type of relationship, which we define dialogic: the one that is established between the different social actors of any communicative act. The dialogicity leads, in fact, much of our social and communicative act, and not only when it assumes the explicit form of conversation. The entire organization of culture is dialogic (cf. Lotman, 1985).

Hence a third type of relationship, that in design involves the designer and the user: it is a dialogical relationship, not directed but mediated by the product. In this sense, the artefacts are presented as the time when the designing logic (the purposes and criteria that support the project idea) interacts with the user logic (the way in which artefacts are understood, appreciated and used).

\section{From the product of sense to the effect of sense}

The satisfaction obtained by using a product, whatever it is, is of paramount importance for the user. Satisfaction is a "subjective" requisite and covers the anthropological, psychological and perceptible dimen- 
sion of the human-environment and human-artefacts relationship. It is not difficult to see how the satisfaction degree of a product is largely determined (a) by the relationship between the sensory nature of expression and the cognitive nature of content, (b) by the dialogical relationship between different semantic worlds and between different communicative intentions; and in design, (c) by the relationships between the objective of sense of the designer, the nature of the product of sense and the effects of sense on the user (Zingale, 2009).

All this is even more evident when you move from the "traditional" idea of product - a tangible object, provided with form and matter - to that of the Product-Service System (PSS), where the artefact's form of expression is largely immaterial, although still mediated by communication tools, organized environments, forms of social transactions, etc. Here, the semiotic mediation is aimed to the production of decisions to be taken on lifestyles and behaviour practices to adopt. No more products to be owned, but actions to be implemented. In PSS the form of items, the shape of communication and the form of service are a single interference set.

This interference set involves an update of the aesthetic-semiotic approach to design. In fact, although as regards the "product-item" the aesthetic dimension passes entirely through the formal and material qualities of the artefact, as regards the "product-service" the aesthetic dimension follows other routes. The problem arises when it is necessary to study the sense of a product, taking into account not only its structure, as a concluded and defined body, but especially the open set of its possible effects: not only its shape but the consequences that could arise from it (Peirce, 1878, CP 5.402).

\section{Observation of the logic of events}

If, in this way, a product can be thought of as a "text" defined by boundaries, with its own semantic consistency and syntactic cohesion (cf. Marrone 2009), then, on the other hand, the product-service is indeed a "semiotic text", but its borders are variable and its outcome undefined. It is a text open to occasional events of experience, in which the pragmatic dimension - the interaction - appears as a decisive value.

The semiotic study is, in this case, approaching the ethnographic observation methods, where the user experience is being investigated. Experience as logic of events: the actions that are performed during the use of a PSS and the pragmatic concatenations that the PSS organization produces.

This observational character may be applied in three phases:

- before the project, in the observation, of ethnographic or ethno-semiotic kind (cf. Marsciani 2007), of the existing social practices;

- $\quad$ during the project, in the verification and testing phases of PSS;

- after the project, in analysis of already tested PSS case studies, with more or less positive results.

In particular, the observation of the user experience should include:

- levels of understanding: what and how the service offered is understood by the user;

- expectations about the expected benefit: what the user shows to be able to do or wants to get;

- attitudes: how the user is approaching it and what types of conduct he puts in place;

- choices of action: what the user chooses to do and why;

- programmed responses: whether and how the user respects the order of actions in the design program;

- interpretative cooperation: what the user can add to the use modality of the service;

- interpretative responses: the reactions and judgments made about the service received.

\section{From experience to design}

Here, the semiotic way of looking at things is helping to translate the observed data in social practices, in design choices that can outline innovative, efficient and satisfactory solutions. The difficulty of this translation is mainly in the degree of novelty of the PSS, or in the implicit request of breaking behavioural patterns and models. As regards the use of products, in fact, individual and social habits are pretty entrenched and, generally, implemented on the basis of automatic or traditional adjustments.

Instead, the PSS innovation requires: 
- a cognitive shift towards unknown habits and programs of use;

- a semantic reformulation and then a reconfiguration of the values traditionally associated with artefacts;

- a didactic clearness of communication forms of the PSS.

For this reason, the elaboration of plausible solutions will mainly concern the way in which the PSS is able to design the new use of artefacts, marking a difference with tradition. In particular:

- new habits that the subject-users must make their own;

- access roads to the PSS, which deviate from traditional ways of acquiring a product;

- and sharing rules of the PSS, or the idea of shared and intersubjective ownership;

- learning forms of new use modalities;

- elements of satisfaction derived from PSS and that only this one can provide.

\section{Sense and satisfaction}

This last aspect leads us to the heart of one of the most critical points in the PSS proposal. Indeed, if the PSS marks a discontinuity with traditional forms of use and consumption of products, and if this discontinuity is aimed at transition to more sustainable forms, in which aspects of PSS will a user identify the source of the actual benefit?

So we return to what was said on semiotic relations at the beginning. The plane of expression plays a strategic role in all forms of communication. It is both what represents the content and what introduces the content. In PSS the plane of content is to be identified (a) in either services offered to users, and then in the actions of use that it requires, in the benefits which it brings about in terms of performance, and especially (b) in the request for change of lifestyles in view of a commitment, whose benefit is collective.

But in eco-efficient PSS it is possible to draw a third line of sense, which may decide the very success of the PSS. We can imagine it as the line of satisfaction, the one that affects the sensory, emotional and motivational sphere of the user.

Some may say that the existence of this third line of sense is what has always characterized design, which has entrusted its aesthetic sphere with the task of giving a differential value to industrial products. What changes here, however, is the role of the aesthetic function. Recalling Jakobson's functions of language (Jakobson, 1963), the aesthetic function is the one concerning the form of the message, its expression.

If we assume that the aesthetic function has the task of catching the sensory and cognitive attention, in PSS it should be designed and developed in two further ways: first as the gateway that helps the userrecipient to understand the overall sense of PSS, and secondly as a form of introduction to the instructions of use and the manner in which the user enters the game of untold social relationships.

This easily shows us how the aesthetic function of PSS is largely responsible for the communication and understanding of the profound values of the eco-efficient project: it can be entrusted with a task of great responsibility in the establishment of design practices, in view of the transition to sustainability.

\section{Pragmatics of aesthetic function}

Hence, the proposal of a more pragmatic and social view of aesthetic function. In fact, although there is, among the innovative features of the PSS, the overtaking of consumption as possession, the primacy of service on product, favouring the idea of sharing assets, the aesthetic function extends from objectivity of things to types of relationship between subjects (between service providers and users, between users of the same service).

But what does "to take care of the aesthetic function in human relations" mean?

It means, first of all, emphasize the dialogical nature of these relationships and, therefore, bring attention to the forms in which dialogicity is expressed. Not only through acts of speech, as in normal conversation, but also through a different perspective that subjects-users have to develop using products. Any use, as a matter of fact, leaves a trace of the user on the objects. In shared artefacts these tracks do not disappear, they are on the contrary foreseen by the structure of the product: it belongs to everyone and it is for everyone. This means that the product should be thought of as the place where the user interacts directly or by implication, with other users, the place where he can feel part of a community. In this per- 
spective, each product needs to be designed as part of a common language, a language that everyone can talk and, above all, through which each subject has the opportunity to communicate with other subjects.

This effect of sense (community feeling) must be understood by design as the priority and most communicable content. Again, it is the form of expression of the product that represents and introduces to such content.

\section{Future research directions}

In this paper we have outlined a possible new frontier for the research in design and semiotic. The working hypothesises we defined have of course to be consolidated. However the opinion of the authors is that this is an important and fertile research ground.

Important, because of the role that aesthetic can and must play in the transition towards sustainability. In fact it is not enough to develop sustainable innovations, but it is necessary to make these innovations to be perceived as better than the existing and unsustainable panorama of artefacts.

Fertile, because it opens a debate that does not involve only sustainability, but is related to the foundation of the design role itself.

\section{Bibliography}

Behrendt, S., Jasch, C., Kortman, J., Hrauda, G., Pfitzner, R., and Velte, D. (2003) Eco-Service Development: Reinventing Supply and Demand in the European Union, Sheffield: Greenleaf Publishing.

Belk, R.W. (1985) "Materialism: Trait Aspects of Living in the Material World” Journal of Consumer Research, vol. 12, pp. 265-280.

Bianchi, C., Montanari, F., and Zingale S. (eds.) (2010) La Semiotica e il Progetto 2, Milano: FrancoAngeli.

Bonfantini, M.A. (2000) Breve Corso di Semiotica, Napoli: Esi.

Brezet H., Bijma, A.S., Ehrenfeld, J., Silvester, S. (2001) The design of eco-efficent services. Methods, tools and review of the case study based "Designing eco-efficent Services" project, Report for Dutch Ministries of Environment (VROM).

Ceschin, F. (2009) Il Potenziale Ruolo della Semiotica nella Diffusione di Sistemi di Prodotto Servizio (PSS), working paper made for the course "Semiotcs and Design”, PhD programme in Design, Politecnico di Milano.

Ceschin, F., and Vezzoli, C. (2010) "The Role of Public Policy in Stimulating Radical Environmental Impact Reduction in the Automotive Sector: The Need to Focus on Product-Service System Innovation”, Int. J. Automotive Technology and Management, vol. 10, no. 2/3, pp. 321-341.

Charter, M., and Tischner, U. (2001) Sustainable Solutions. Developing Products and Services for the Future, Sheffield: Greenleaf publishing.

Davoli, L., Fiocchi F., and Lin, J. (2008) Vehicle Design Summit 2.0: introduction of sustainable mobility systems in emerging contexts. Master degree thesis, Politecnico di Milano, Faculty of Design.

Deni, M., and Proni, G. (eds.) (2008) La Semiotica e il Progetto, Milano: FrancoAngeli.

Factor 10 Club (1994) Declaration of the Factor 10 Club, available at http://www.techfak.unibielefeld.de/techfak/persons/walter/f10/declaration94.html.

Goedkoop, M., van Halen, C., te Riele, H., Rommes, P. (1999) Product Services Systems, Ecological and Economic Basics, report 1999/36. The Hague: VROM.

Haake, J., and Jolivet, P. (2001) "Some Reflections on the Link Between Production and Consumption for Sustainable Development”, Int. J. Sustainable Development, vol. 14, no. 1, pp. 22-32.

Hacker, A. (1967) “A Defence (or at Least an Explanation) of American Materialism” Sales Management, March 1967, pp. 31-33.

Halkier, B. (1998) Miljbhensyn i Forbrug. Erfaringer og Forhandlinger i Ambivalente Hverdagsliv, Roskilde: Institut for Miljb, Teknologi og Samfund, Roskilde Universitets.

Hjelmslev, L. (1943) Prolegomena to a Theory of Language, Madison: Wisconsin Univ. Press.

Jackson, T., and Marks, N. (1999) "Consumption, Sustainable Welfare and Human Needs - with Reference to UK Expenditure Patterns Between 1954 and 1994” Ecological Economics, vol. 28, no. 3, pp. 421-441.

Jakobson, R. (1963) Essais de Linguistique Générale, Paris: Minuit.

Kilbourne, W.E., Beckmann, S.C., and Lewis, A. (2001) "A multinational examination of the role of the dominant social paradigm in environmental attitudes of university students” Environment and Behavior, vol. 33, no. 2, pp. 209-229.

Lotman, J.M. (1985) la Semiosfera. L’Asimmetria e il Dialogo nelle Strutture Pensanti, Venezia: Marsilio. 


\section{Sustainability in Design: NOW!}

Manzini, E., Collina, L., and Evans, S. (eds.) (2004) Solution oriented partnership, Cranfield: Cranfield University. Manzini, E., and Vezzoli, C. (2001) "Strategic design for sustainability", paper presented at the TSPD conference, Amsterdam, The Netehrlands.

Marsciani, F. (2007) Tracciati di Etnosemiotica, Milano: FrancoAngeli.

Marrone, G. (2009) L'invenzione del testo, Bari-Roma: Laterza.

Max-Neef, M. (1991) Human Scale Development: Conception, Application and Further Reflections, New York: The Apex Press.

Max-Neef, M. (1995) “Economic growth and quality of life: a threshold hypothesis”, Ecological Economics, vol. 15, pp. 115-118.

Mont, O. (2002) “Clarifying the concept of product-service system”, Journal of Cleaner Production, vol. 10, no. 3, pp. 237-245.

Mont, O. (2004a). Product-service systems: panacea or myth? Doctoral dissertation, IIIEE Lund University.

Mont, O. (2004b) “Institutionalisation of Sustainable Consumption Patterns Based on Shared Use”, Ecological Economics, vol. 50, no. 1-2, September 2004, pp. 135-153.

Mont, O., and Lindhqvist, T., (2003) “The Role of Public Policy in Advancement of Product Service Systems”, Journal of Cleaner Production, vol. 11, no. 8, pp. 905-914.

Mont, O., and Plepys, A. (2008) “Sustainable Consumption Progress: Should We Be Proud or Alarmed?”, Journal of Cleaner Production, vol. 16, pp. 531-537.

Peirce, Ch. S. (1878) “How to make our Ideas clear”, in Writings, vol. III, Bloomington: Indiana Univ. Press, 1986.

Røpke, I. (1999) “The Dynamics of Willingness to Consume”, Ecological Economics, vol. 28, pp. 399-420.

Schmidt-Bleek, F. (1996) MIPS Book or the Fossil Makers - Factor 10 and More, Berlin, Boston, Basel.

Stahel, W.R. (1986) "Hidden Innovation: R\&D in a Sustainable Society”, Science and Public Policy, vol. 13, no. 4, pp. 196-203.

Stahel, W.R. (1989) The Limits to Certainty: Facing Risks in the New Service Economy, Dordrecht: Kluwer Academic Publishers.

Stahel, W.R. (1997) “The Functional Economy: Cultural and Organizational Change”. In: Richards (eds.) The Industrial Green Game, Washington DC: National Academy Press.

Tamborrini, P. (2009) Design sostenibile. Oggetti, sistemi e comportamenti, Milano: Mondadori Electa.

Tischner U., Rayan C., Vezzoli C.,(2009) “Product- Service Systems”. In Crul M., Diehl J.C. (eds) Design for Sustainability (D4S): A Step-By-Step Approach. Modules, Paris: United Nations Environment Program (UNEP).

Tukker, A., and Tischner, U. (eds.) (2006). New business for Old Europe. Product Services, Sustainability and Competitiveness, Sheffield: Greenleaf publishers.

United Nations Environmental Programme, UNEP. (2002) Product-Service Systems and Sustainability. Opportunities for sustainable solutions, Paris: UNEP, Division of Technology Industry and Economics, Production and Consumption Branch.

Van Halen, C., Vezzoli, C. \& Wimmer, R. (eds). (2005) Methodology for Product Service System. How to develop clean, clever and competitive strategies in companies, Assen: Van Gorcum.

Vezzoli, C. (2007) System design for sustainability. Theory, methods and tools for a sustainable "satisfactionsystem” design, Rimini: Maggioli Editore.

Vezzoli, C. and Ceschin, F. (2008) “Modelli di business alternative per l'industria automobilistica” Trasporti \& Cultura, Campanotto Editore, vol. 21, pp. 46-57.

World Business Council for Sustainable Development (WBCSD) (1996) Eco-efficient leadership, Final report of the Working Group on eco-efficiency, Geneva: World Business Council for Sustainable Development.

Zingale, S. (2009) Gioco, dialogo, design, Milano: ATì.

\section{About the authors}

Fabrizio Ceschin, master degree in Industrial Design at Politecnico di Milano, since 2006 works as researcher in the Design and system Innovation for Sustainability (DIS) research unit, inside the Design department (INDACO) of Politecnico di Milano, dealing with innovation, design and development of products, services and systems, targeting sustainable results. He is currently a $\mathrm{PhD}$ candidate in Design, working on the issue of 'design and radical changes for sustainability'. He took part in several research projects commissioned by companies and researches funded by EU (among which 'SCORE!, Sustainable Consumption Research Exchange!'). He is currently the Project Manager of the EU funded research 'LeNS, the Learning Network on Sustainability'.

Contact details: Politecnico di Milano, INDACO Department, Design and system Innovation for Sustainability, via Durando 38/a, 20158 Milan, Italy; tel: +39 022399 7203; email: fabrizio.ceschin@polimi.it

Carlo Vezzoli, for 15 years he has been researching and teaching on design for sustainability. At the Politecnico di Milano University he the head of the Research Unit Design and system Innovation for Sustainability (DIS) and head of the Design and Sustianability Lab (DeSOS) as well as professor of Design for Sustainability. Among others public and private funded projects currently he is the co-ordinator of the Learning Network on Sustainability (LeNS, www.lens.polimi.it) funded by the Asia Link Programme, European Commission. 
Contact details: Politecnico di Milano, INDACO Department, Design and system Innovation for Sustainability, via Durando 38/a, 20158 Milan, Italy; tel: +39 022399 5983; email: carlo.vezzoli@polimi.it

Salvatore Zingale, graduated in Semiotics by the Università di Bologna (1981). Teaching experience at the school ISA (Art and Design Institute) in Monza from 1988 to 2000. Tenured university teacher since 1996. Researcher and Professor in Semiotics at the Politecnico di Milano from 2006.

Contact details: Politecnico di Milano, INDACO Department, Communication Design, via Durando 38/a, 20158 Milan, Italy; tel: +39 022399 5985; email: salvatore.zingale@polimi.it

\section{Acknowledgment}

The paper is the result of the collaboration between the three authors; nevertheless Ceschin wrote section "Eco-efficient Product-Service System (PSS): user acceptation barriers", and sub-sections "Insights from case studies" and "A design research working hypothesis"; Vezzoli wrote sections "Eco-efficient Product-Service System (PSS) innovation: a promising approach to sustainability”, “A potential role of aesthetic in enhancing the attraction, acceptation and satisfaction related to eco-efficient PSS?" (introductive part), and "Future research directions"; Zingale wrote section "Semiotics, aesthetic and eco-efficient PSS”. 